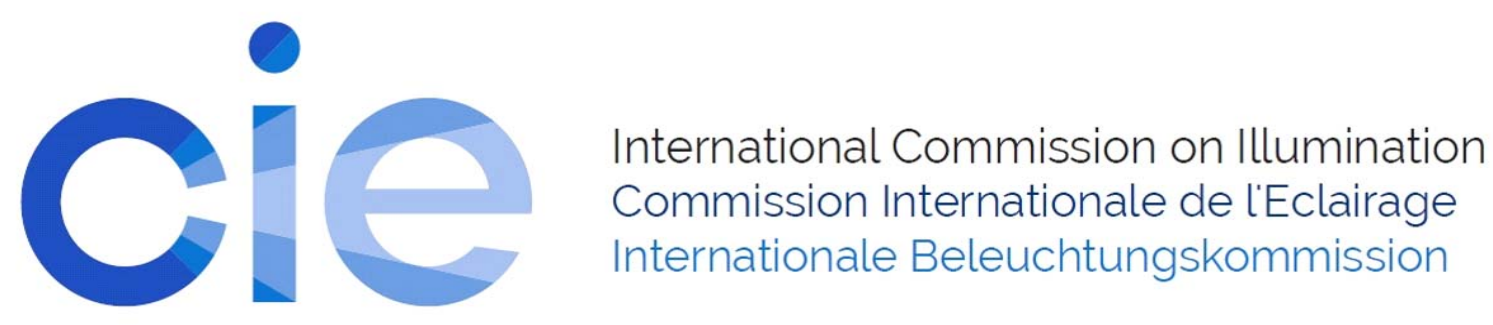

P0147

\title{
PREFERABLE LIGHTING FOR APPEARANCE OF WOMEN'S FACIAL SKIN
}

\author{
Shino Okuda et al.
}

DOI 10.25039/x46.2019.PO147

from

CIE x046:2019

Proceedings

of the

29th CIE SESSION

Washington D.C., USA, June 14 - 22, 2019

(DOI 10.25039/x46.2019)

The paper has been presented at the 29th CIE Session, Washington D.C., USA, June 14-22, 2019. It has not been peer-reviewed by CIE.

(C) CIE 2019

All rights reserved. Unless otherwise specified, no part of this publication may be reproduced or utilized in any form or by any means, electronic or mechanical, including photocopying and microfilm, without permission in writing from CIE Central Bureau at the address below. Any mention of organizations or products does not imply endorsement by the CIE.

This paper is made available open access for individual use. However, in all other cases all rights are reserved unless explicit permission is sought from and given by the CIE.

CIE Central Bureau

Babenbergerstrasse 9

A-1010 Vienna

Austria

Tel.: +4317143187

e-mail: ciecb@cie.co.at

www.cie.co.at 


\title{
PREFERABLE LIGHTING FOR APPEARANCE OF WOMEN'S FACIAL SKIN
}

\author{
Okuda, S. ${ }^{1}$, Okajima, K. ${ }^{2}$ \\ ${ }^{1}$ Doshisha Women's College of Liberal Arts, Kyoto, JAPAN, \\ 2 Yokohama National University, Yokohama, JAPAN \\ sokuda@dwc.doshisha.ac.jp
}

DOI 10.25039/x46.2019.PO147

\begin{abstract}
This study aims to reveal the preferable lighting condition on the appearance of woman's facial skin. We conducted an experiment on the appearance of woman's face with and without makeup under some lighting conditions. The facial skin conditions of the female model consisted of three patterns, without makeup, with makeup in orange and with makeup in pink. Participants evaluated face appearance in terms of "naturalness," "activity", "sophistication" and "preference". According to the results, the facial skin without makeup and with "natural" makeup look good under $4000 \mathrm{~K}$ and $5000 \mathrm{~K}$ in negative duv, and facial skin of all types looks active under $3000 \mathrm{~K}$. In addition, the evaluations of activity of the face without makeup correlated with the preference index for Japanese complexion PS, whereas other evaluations of preference have no correlation with $P S$.
\end{abstract}

Keywords: Light color, appearance, Makeup, Facial skin

\section{Introduction}

The appearance of the skin is extremely important for women and various products aim at improving the skin condition. However, the appearance of the facial skin depends on the lighting as well as on the cosmetics being applied. Indeed, cosmetics can alter the perceived color of the skin which affects the visual evaluation.

Previous our study reported that some LED lamps with low color temperature is better for perceived impression of a woman's face when compared to high color temperature LED lamps (YAMAGUCHI, et al., 2012). Also, we found the optimal combinations of the light color and the type of makeup that were preferred on the appearance of woman's facial skin (OKUDA, et al., 2017). On the other hand, it was reported that a preference index PS for Japanese women complexion (YANO, et al., 1998) was suitable for evaluating appearance under various kinds of light sources including fluorescent lamps defined by CIE15.3, 2004 and LED lamps, white LEDs and RGB LEDs (YANO, et al., 2016).

To reveal the preferable lighting condition on the appearance of woman's facial skin, we conducted an experiment on the appearance of woman's face with and without makeup under some lighting conditions with different correlated color temperature (CCT) and distance to the blackbody locus (duv).

\section{Methods}

\subsection{Visual stimuli}

First, we set 20 kinds of lighting conditions with four levels of CCT $(3000 \mathrm{~K}, 4000 \mathrm{~K}, 5000 \mathrm{~K}$, $6700 \mathrm{~K})$ and 5 kinds of $\operatorname{duv}(-0.010,-0.005,0,+0.005,+0.010)$ in each CCT condition, using 6 RGB LED lamps [iColor Cove MX Powercore, Philips Color Kinetics] and 10 white LED lamps [iW CoveMX Powercore, Philips Color Kinetics] with 3 kinds of LED in different correlated color temperature. Table 1 shows the color rendering characteristics: $R_{a}(\mathrm{CIE} C \mathrm{CRI}), R_{15}$ (for Japanese complexion, JIS), $R_{f}$ (CIE 224) and PS (Preference Index of Japanese complexion) of each lighting condition.

Secondly, we asked a female university student to be a model as the visual object. She was 22 years old. Her facial skin colors with and without cosmetic foundation and the average of Japanese women's facial skin colors with cosmetic foundation in 2011 were shown in Table 2. 
We prepared three patterns of facial skin, without makeup, with "natural" makeup in orange lipstick and brusher and with "cute" makeup in pink lipstick and brusher. Figure 1 shows the faces with three patterns of makeup under the lighting conditions, where $C C T=5000 \mathrm{~K}$ and $d u v=0$.

Table 1 - Color rendering characteristics: Ra (CIE CRI), R15 (for Japanese complexion, JIS), Rf (CIE 224) and PS (Preference Index of Japanese complexion)

\begin{tabular}{c|c|c|c|c|c|c|c|c|c|c}
\hline Lighting Conditions & $\boldsymbol{C C T}(\mathrm{K})$ & $\boldsymbol{d} \boldsymbol{d} \boldsymbol{v}$ & $\boldsymbol{x}$ & $\boldsymbol{y}$ & $\boldsymbol{u}^{\prime}$ & $\boldsymbol{V}$ & $\boldsymbol{R a}$ & $\boldsymbol{R} 15$ & $\boldsymbol{R} \boldsymbol{( C I E 2 2 4 )}$ & $\boldsymbol{P S}$ \\
\hline $3000 \mathrm{~K}-10$ & 3004 & -0.010 & 0.423 & 0.376 & 0.254 & 0.507 & 75 & 80 & 85 & 88 \\
\hline $3000 \mathrm{~K}-05$ & 2997 & -0.005 & 0.430 & 0.390 & 0.252 & 0.515 & 86 & 88 & 89 & 94 \\
\hline $3000 \mathrm{~K}$ & 3005 & 0.000 & 0.436 & 0.403 & 0.251 & 0.521 & 91 & 82 & 89 & 90 \\
\hline $3000 \mathrm{~K}+05$ & 2996 & 0.005 & 0.445 & 0.421 & 0.249 & 0.529 & 91 & 88 & 80 & 95 \\
\hline $3000 \mathrm{~K}+10$ & 3008 & 0.010 & 0.453 & 0.436 & 0.247 & 0.536 & 88 & 85 & 78 & 94 \\
\hline $4000 \mathrm{~K}-10$ & 3999 & -0.010 & 0.374 & 0.352 & 0.231 & 0.489 & 96 & 94 & 90 & 98 \\
\hline $4000 \mathrm{~K}-05$ & 4003 & -0.005 & 0.377 & 0.364 & 0.228 & 0.495 & 96 & 94 & 89 & 95 \\
\hline $4000 \mathrm{~K}$ & 4004 & 0.000 & 0.380 & 0.376 & 0.225 & 0.501 & 87 & 89 & 88 & 90 \\
\hline $4000 \mathrm{~K}+05$ & 3998 & 0.005 & 0.384 & 0.391 & 0.222 & 0.508 & 86 & 90 & 89 & 89 \\
\hline $4000 \mathrm{~K}+10$ & 4006 & 0.010 & 0.387 & 0.402 & 0.220 & 0.513 & 86 & 91 & 90 & 90 \\
\hline $5000 \mathrm{~K}-10$ & 5003 & -0.010 & 0.343 & 0.331 & 0.218 & 0.474 & 88 & 94 & 91 & 97 \\
\hline $5000 \mathrm{~K}-05$ & 4997 & -0.005 & 0.344 & 0.341 & 0.215 & 0.479 & 96 & 96 & 91 & 93 \\
\hline $5000 \mathrm{~K}$ & 4997 & 0.000 & 0.345 & 0.351 & 0.212 & 0.485 & 91 & 91 & 89 & 84 \\
\hline $5000 \mathrm{~K}+05$ & 4992 & 0.005 & 0.346 & 0.363 & 0.208 & 0.490 & 88 & 91 & 90 & 83 \\
\hline $5000 \mathrm{~K}+10$ & 4993 & 0.010 & 0.347 & 0.374 & 0.205 & 0.495 & 87 & 91 & 90 & 82 \\
\hline $6700 \mathrm{~K}-10$ & 6693 & -0.010 & 0.313 & 0.305 & 0.208 & 0.455 & 82 & 89 & 87 & 95 \\
\hline $6700 \mathrm{~K}-05$ & 6707 & -0.005 & 0.312 & 0.312 & 0.204 & 0.459 & 89 & 94 & 88 & 83 \\
\hline $6700 \mathrm{~K}$ & 6703 & 0.000 & 0.311 & 0.321 & 0.200 & 0.464 & 94 & 92 & 88 & 90 \\
\hline $6700 \mathrm{~K}+05$ & 6699 & 0.005 & 0.309 & 0.329 & 0.196 & 0.468 & 92 & 94 & 88 & 80 \\
\hline $6700 \mathrm{~K}+10$ & 6699 & 0.010 & 0.308 & 0.337 & 0.192 & 0.472 & 91 & 94 & 89 & 79 \\
\hline
\end{tabular}

Table 2 - Facial skin colors with and without cosmetic foundation and the average of Japanese women's facial skin colors with cosmetic foundation in 2011

\begin{tabular}{c|c|c|c|c|c}
\hline Visual targets & skin condition & Hue & Value & Chroma & Melanin Index \\
\hline \multirow{2}{*}{ Woman's model of this experiment } & nude & 8.2 YR & 6.59 & 3.09 & 0.93 \\
\cline { 2 - 6 } & with cosmetic foundation & $6.2 \mathrm{YR}$ & 6.45 & 3.51 & 1.25 \\
\hline \multirow{2}{*}{$\begin{array}{c}\text { Woman's model of the experiment } \\
\text { reported in CIE2017 }\end{array}$} & nude & $8.3 \mathrm{YR}$ & 6.46 & 2.95 & 1.10 \\
\cline { 2 - 6 } & with cosmetic foundation & $6.9 \mathrm{YR}$ & 6.47 & 3.17 & 1.14 \\
\hline Average of Japanese women's skin in 2011* & with cosmetic foundation & $5.6 \mathrm{YR}$ & 6.91 & 3.54 & 1.14 \\
\hline
\end{tabular}
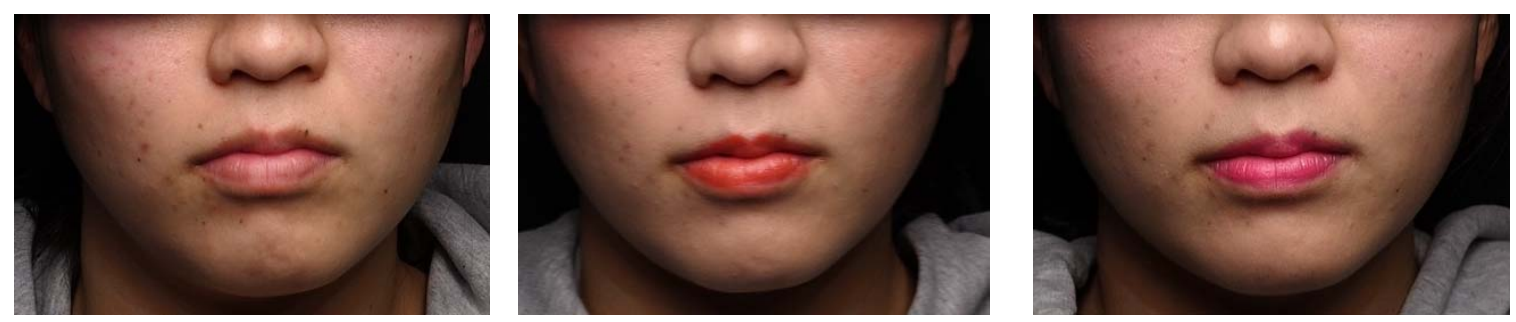

Figure 1 - Faces with three patterns of makeup $(5000 \mathrm{~K}, d u v=0)$

\subsection{Procedure}

Figure 2 shows the experimental space. Participants observed the lower half of the female model's face, especially the lower cheeks, and evaluated "naturalness," "activity," "sophistication" and "preference" with a numerical scale from -10 (bad) to +10 (good). Fifteen females in their twenties participated, and all had normal color vision. 

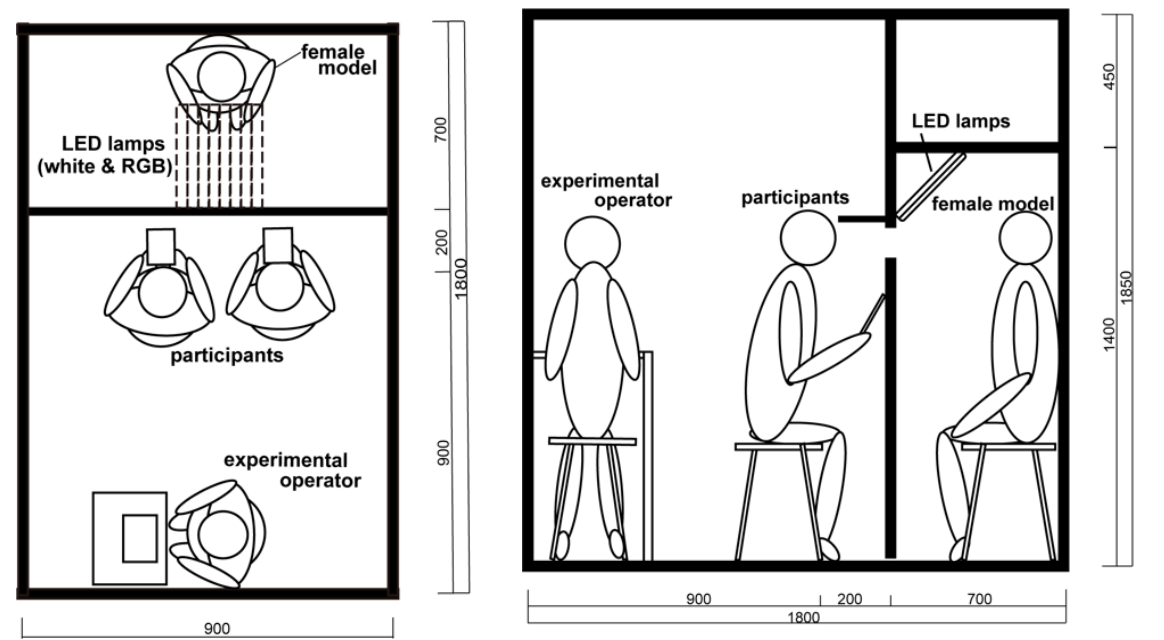

Figure 2 - Experimental space

\section{Results and Discussion}

Figure 3 shows the evaluation results. The evaluations of "naturalness," "sophistication" and "preference" were relatively high under the lighting conditions of $4000 \mathrm{~K}$ and $5000 \mathrm{~K}$ in duv=0.005 but relatively low under the lightings of $3000 \mathrm{~K}$ in all types of facial skin. On the other hand, the "activity" was quite high under the lighting conditions of $3000 \mathrm{~K}$ whereas the facial skin under $6700 \mathrm{~K}$ lighting looks inactive. The lighting conditions in $d u v=+0.01$ were relatively low in all types of facial skin. As compared with the patterns of facial skin, the evaluations of facial skin without makeup were similar to those of facial skin with "natural" makeup.

Figure 4 shows the relationship between the evaluation results and $P S$. It is clear that the evaluations of the activity of facial skin without makeup are correlated with $P S$, but evaluations of preference are not correlated with PS.
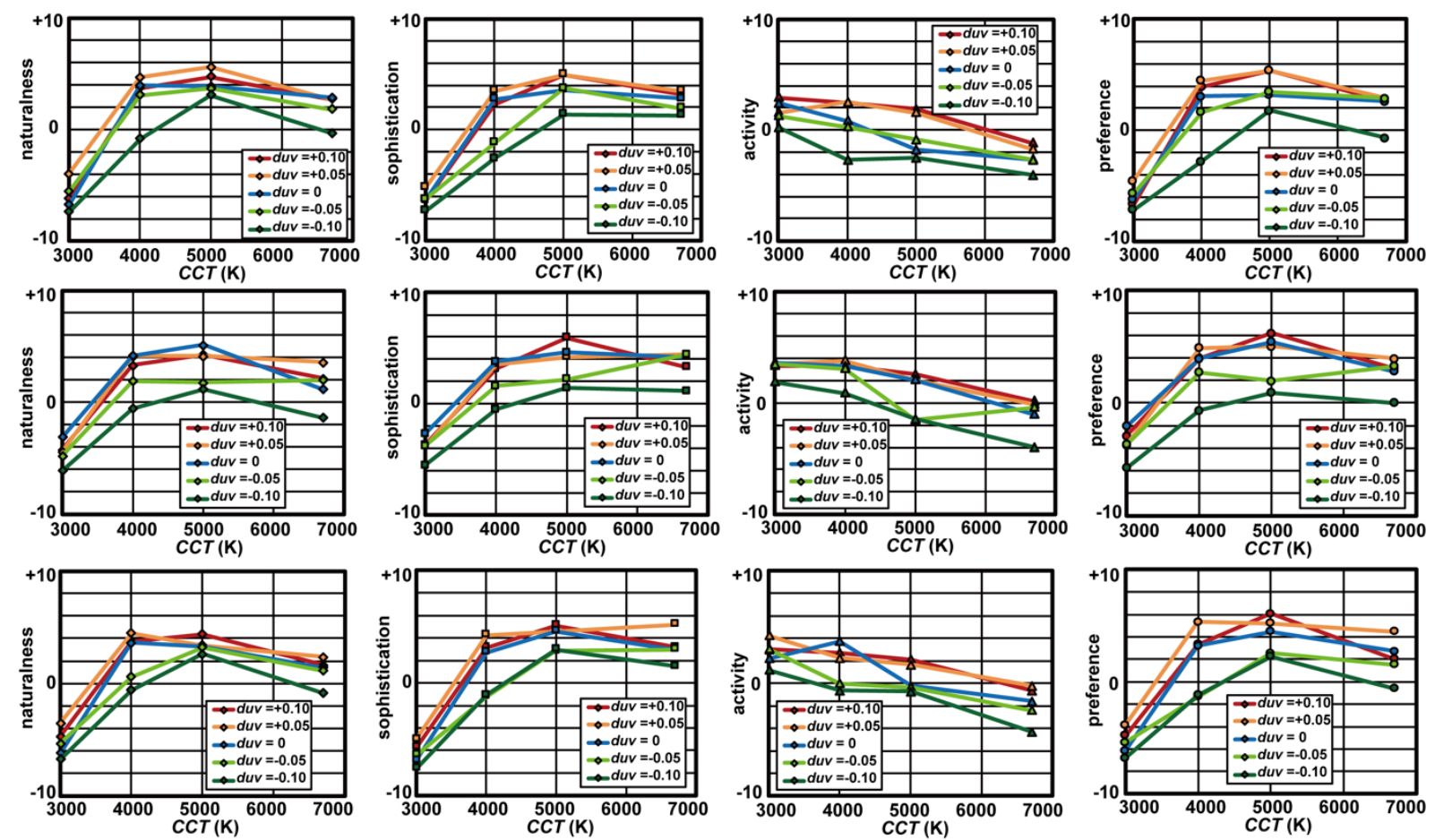

Figure 3 - Evaluation results 

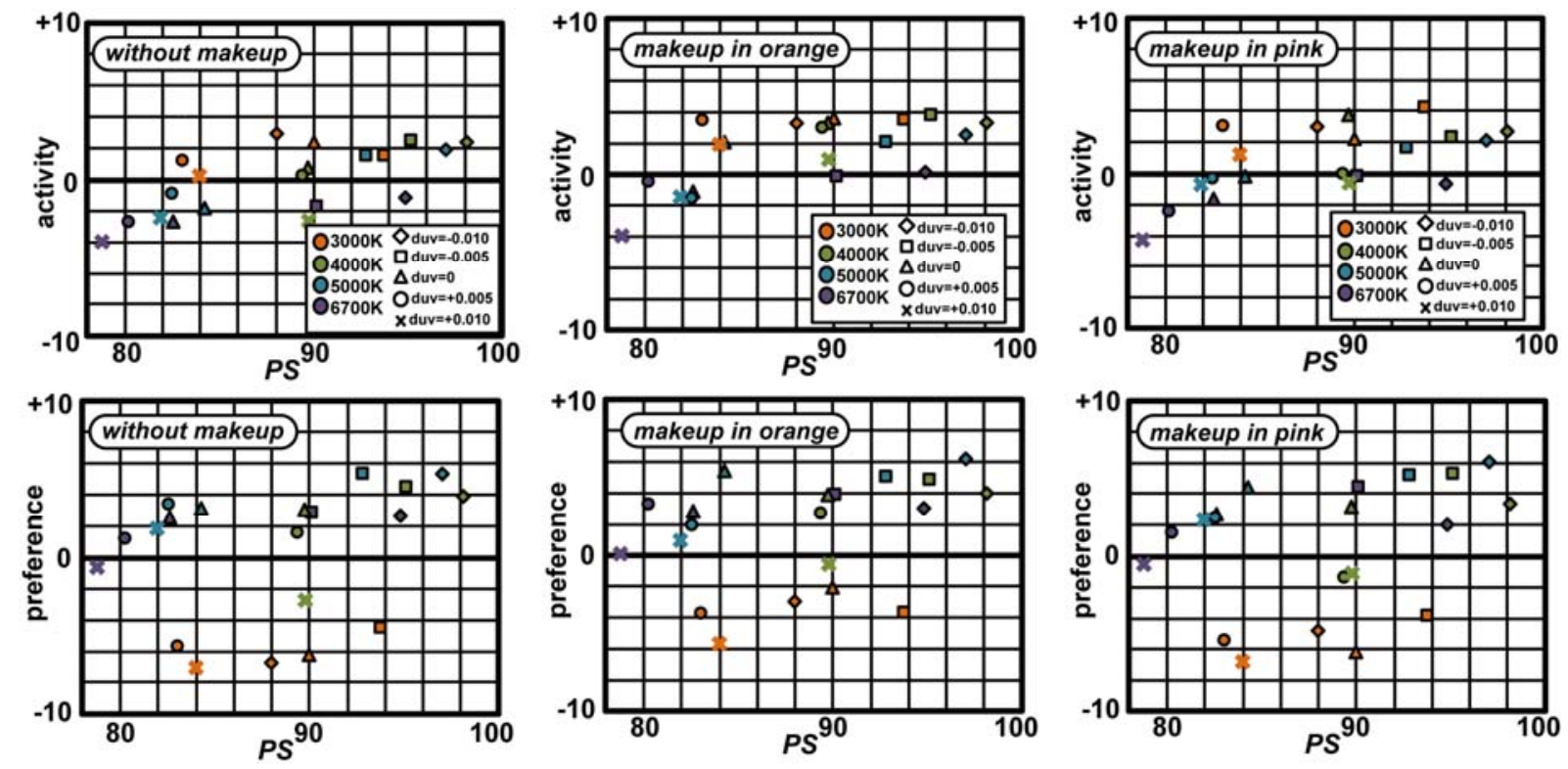

Figure 4 - Evaluation results

Moreover, we analyzed these evaluation data by using a multiple regression; "preference" was used as the response variable, and "naturalness," "activity" and "sophistication" were used as the explanatory variables. As a result, it was derived that the standardized partial regression coefficient of "sophistication" was 0.663 , that of "naturalness" was 0.282 , and that of "activity" was 0.128 . This suggests that the contribution of "sophistication" is much higher than that of "naturalness" or "activity" in "preference" evaluation.

\section{Conclusion}

Facial skin without makeup and with "natural" makeup look good under $4000 \mathrm{~K}$ and $5000 \mathrm{~K}$ in negative duv, and facial skin of all types looks active under $3000 \mathrm{~K}$. In addition, the evaluations of activity of the face without makeup correlated with $P S$, whereas other evaluations of preference have no correlation with PS.

\section{Acknowledgments}

This study was supported by JSPS KAKENHI Grant Number $17 \mathrm{H} 01947$ and $15 \mathrm{H} 05926$. We would like to thank Naho Motomura who was an undergraduate student in D.W.C.L.A for helping.

\section{References}

YAMAGUCHI, S., OKUDA, S. and SAITO, T., 2012, Preferable LED Lamps for Appearance of Skin Color of Human Face, Proceedings of AIC2012, 446-449

YANO, T. and HASHIMOTO, K., 1998, Preference Index for Japanese Complexion Color under Illumination, Journal of the Illuminating Engineering Institute of Japan 82-11, 895-901, (in Japanese)

YANO, T. and HASHIMOTO, K., 2016, Preference Index for Japanese Complexion Under Illuminations, Color Research and Application, 41-2, 143-153

OKUDA, S. and OKAJIMA, K., 2017, Optimal Combination of Light Color and Type of Make-up on Appearance of Women's Facial Skin, Proceedings of CIE2017, 823-826 